
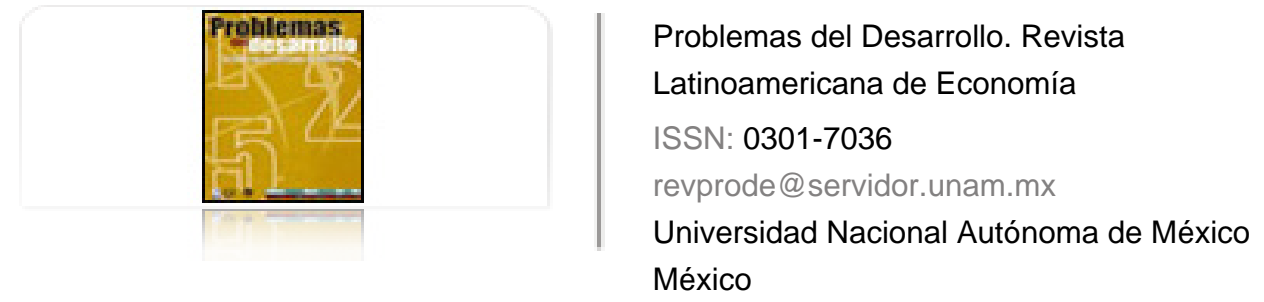

Bekerman, Marta; Rodríguez, Santiago; Sirlin, Pablo

Obstáculos al desarrollo de encadenamientos productivos en América Latina: El caso de los muebles de madera en Argentina

Problemas del Desarrollo. Revista Latinoamericana de Economía, vol. 36, núm. 140, 2005, pp. 113-

141

Universidad Nacional Autónoma de México

Distrito Federal, México

Disponible en: http://www.redalyc.org/articulo.oa?id=11820092006

- Cómo citar el artículo

- Número completo

- Más información del artículo

Página de la revista en redalyc.org

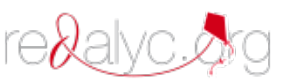

Sistema de Información Científica

Red de Revistas Científicas de América Latina, el Caribe, España y Portugal Proyecto académico sin fines de lucro, desarrollado bajo la iniciativa de acceso abierto 


\section{OBstÁCulos AL DESARROLLO dE ENCADENAMIENTOS PROductivos en AmÉRICA Latina: el CASO de los muebles DE MADERA EN ARgENTINA}

\section{Marta Bekerman* Santiago Rodríguez** Pablo Sirlin***}

Fecha de recepción: 5 de agosto de 2004. Fecha de aceptación: 27 de enro de 2005.

\section{Resumen}

El trabajo plantea la importancia del enfoque sistémico vinculado con el desarrollo y consolidación de encadenamientos productivos como impulso al desarrollo de las economías de América Latina. En ese contexto y dentro del marco teórico de la literatura respecto de las fallas de coordinación y problemas ligados a la aplicación de sistemas nacionales de innovación, el trabajo analiza el caso de los muebles de madera en Argentina. Se observa que éste presenta grandes potencialidades derivadas de ventajas comparadas naturales y una larga tradición productiva. Sin embargo, adolece de fuertes debilidades competitivas, con deficiencias importantes en materia tecnológica, desarrollo institucional y organización industrial, por lo que muestra una pobre inserción exportadora.

Palabras clave: encadenamientos productivos, Argentina, madera, muebles.

* Directora del Centro de Estudios de la Estructura Económica (CENES), Facultad de Ciencias Económi cas, Universidad de Buenos Aires. Correo electrónico: bekerman@econ.uba.ar

** Investigador del CENES, Universidad de Buenos Aires. Correo electrónico: santiago@econ.uba.ar

*** Investigador del CENES, Universidad de Buenos Aires. Correo electrónico: psirlin@econ.uba.ar 


\begin{abstract}
This study establishes the importance of a systemic focus linked to the development and consolidation of production chains as a stimulus to development in the economies of Latin America. In that context and within the theoretical framework of the literature dealing with shortfalls in coordination and problems linked to the application of national systems of innovation, this study analyzes the case of wooden furniture in Argentina. It is observed that this presents great potential derived from the natural comparative advantages and a long productive tradition. However, it suffers from severe competitive weaknesses, with significant deficiencies in technology, institutional development and industrial organization, and therefore registers a poor export position.
\end{abstract}

Key terms: production chains, Argentina, wood, furniture.

\title{
Résumé
}

Le travail présente l'importance du point de vue systémique en liaison avec le développement et avec la consolidation d'enchaînements productifs comme aide au développement des économies en Amérique Latine. Dans ce contexte, et à l'intérieur du cadre théorique de la littérature en rapport avec les erreurs de coordination et des problèmes liés a l'application de systèmes nationaux d'innovation, ce travail analyse le cas des meubles en bois en Argentine. On observe qu'il présente un grand potentiel dérivé des avantages comparés naturels et d'une longue tradition productive. Cependant, il souffre de fortes faiblesses de concurrence, avec des déficiences importantes en matière de technologie, de développement institutionnel et d'organisation industrielle, raison pour laquelle il fait preuve d'une insertion exportatrice pauvre.

Mots clés: enchaînements productifs, Argentine, bois, meubles.

\section{Resumo}

O trabalho mostra a importancia do enfoque sistemático vinculado ao desenvolvimento e consolidação de encadeamentos produtivos como impulso ao desenvolvimento das economias da América Latina. Nesse contexto e dentro do marco teórico da literatura ao respeito dos erros de coordenação e problemas relacionados à aplicação de sistemas nacionais de inovação, o trabalho analisa o caso dos móveis de madeira na Argentina. Percebe-se que este apresenta grandes potencialidades derivadas das vantagens comparadas naturais e uma antiga tradição produtiva. Porém, tem grandes fraqueças competitivas, com importantes deficiências tecnológicas, desenvolvimento institucional e organização industrial, como consequência apresenta uma pobre inserção exportadora.

Palavras chave: encadeamentos produtivos, Argentina, madeira, móvies. 


\section{Introducción}

urante las últimas décadas se produjeron importantes transformaciones en el escenario internacional que han modificado bruscamente las condiciones de inserción externa y la presión competitiva a la que se enfrentan las empresas de los países latinoamericanos, especialmente las pequeñas y medianas. Esto plantea la necesidad de comprender fenómenos económicos ligados a la configuración de nuevas relaciones entre compañías que - a partir de un enfoque sistémico vinculado con los problemas tecnológicos y la existencia de fallas de coordinación- permitan entender las limitaciones para la configuración de encadenamientos productivos, pues enfoques tradicionales basados en la empresa, o aun en las ramas productivas, ofrecen sólo una versión parcial de los determinantes de la competitividad.

Desde una perspectiva ortodoxa, la apertura comercial, la desregulación de la economía y el cuidado de los fundamentals macroeconómicos se presentan como condiciones suficientes para alcanzar un proceso sostenido de crecimiento que impulsarían una eficiente asignación de recursos y facilitarían la transferencia internacional de tecnología, lo que permitiría reducir esta brecha y asegurar elevados niveles de inserción exportadora y competitividad. Sin embargo, por diversas razones, la de los distintos sectores productivos plantea desafíos que van mucho más allá de los aspectos señalados.

En primer lugar, por la existencia de economías de escala y de brechas tecnológicas en distintas etapas de la cadena de valor que pueden llegar a impedir la consolidación de la misma. El conocimiento se presenta, en muchos casos, imperfectamente transable en el nivel internacional, y las capacidades individuales de las empresas y las acumuladas en el entorno constituyen factores clave para explicar el desarrollo tecnológico de los distintos países.

Las brechas de tecnología y escala no se encuentran de manera homogénea en toda la cadena de valor, sino que afectan a ciertos eslabones particulares. De allí que, en los últimos años, se ha manifestado en algunos sectores una tendencia a la concentración de las rentas en ciertos eslabones de dichas cadenas (desarrollo de tecnologías de producto - en particular el diseño—, logística y comercialización) dominadas generalmente por grandes empresas de países desarrollados.

En segundo lugar, aparecen limitaciones de naturaleza institucional y, en particular, la debilidad de ciertos mercados —o su ausencia—, resultado de problemas de información y de fallas de coordinación que puede dar lugar a una situación de equilibrios múltiples en

\section{Désaarrollo}


la cual, sin una intervención pública adecuada, la economía puede ubicarse en un punto de menor bienestar que el óptimo. ${ }^{1}$

Este argumento adquiere especial relevancia para los países latinoamericanos, que pueden quedar atrapados en un círculo vicioso, en el cual los bajos niveles de desarrollo de los mercados den lugar a imperfecciones de información y esto genere instituciones que impidan, a su vez, el desarrollo de los mercados (Hoff y Stiglitz, 2001).

Es necesario señalar el vínculo existente entre las fallas de coordinación y las debilidades tecnológicas, pues el desarrollo del Sistema Nacional de Innovación requiere de la interacción entre las empresas, y con las instituciones del entorno. De ese modo, dichas fallas limitan, en numerosos casos, la inversión en desarrollo y absorción de nuevas tecnologías.

Los aspectos señalados no afectan en forma homogénea a los distintos sectores económicos, sino que generan una profunda heterogeneidad entre ellos según sea "el régimen competitivo y tecnológico" en el que funciona cada mercado (Katz, 1999). Se plantea, entonces, la necesidad de trabajar con dimensiones desagregadas que permitan identificar los procesos que no serían observables en un nivel más global; de analizar las debilidades que presenta cada sector o encadenamiento productivo y avaluar las estrategias políticas que deberían aplicarse para alcanzar mayor competitividad sistémica.

En ese marco, el presente trabajo analizará la situación de un encadenamiento productivo ligado a la existencia de ventajas comparativas naturales en el contexto de un país latinoamericano: los muebles de madera en Argentina. Este encadenamiento resulta de especial relevancia por diversos motivos.

Primero, un conjunto de países en vías de desarrollo (del sudeste asiático, Brasil y México) han evidenciado una vertiginosa inserción internacional durante la última década y pasaron a ocupar posiciones importantes entre los principales exportadores mundiales. Esto muestra las potencialidades de ese sector para este tipo de naciones.

Segundo, la disponibilidad de regiones aptas para la forestación.

Tercero, se trata de una industria intensiva en mano de obra, integrada principalmente por pequeñas y medianas empresas (PYMES), con una importante presencia en la mayoría de las regiones del país. Es, asimismo, una fuerte generadora de empleo en el caso de algunas economías regionales, como en las provincias de Santa Fe (Cañada de Gómez y Esperanza) o Formosa (departamento de Pirané).

A pesar de esas potencialidades, el encadenamiento productivo de los muebles de madera presenta bajo nivel de desarrollo en Argentina, con deficiencias importantes en materia tecnológica, de desarrollo institucional y organización industrial, lo que provoca una pobre inserción exportadora. Intentaremos, pues, determinar cómo los factores señalados limitan el desarrollo del encadenamiento en los niveles interno e internacional, así como

Hoff y Stiglitz (2001), Rodrik (1994); véase, además, sección acerca de marco teórico. 
las políticas que deberían aplicarse para alcanzar dicho desarrollo. En este contexto, haremos referencias a la situación que presenta el sector en Brasil.

El trabajo se organiza en cinco secciones. En la inicial se presenta el marco teórico. En la segunda se presenta el sector y su encadenamiento productivo. En la siguiente se consideran las principales características y la dinámica reciente del sector en el nivel mundial. En el cuarto apartado se realiza un análisis de las principales limitaciones para el desarrollo del sector en Argentina, basado en información bibliográfica y en un estudio de campo. Finalmente, se presentan conclusiones y recomendaciones.

\section{Marco teórico}

Este trabajo se basa en distintos cuerpos de literatura. En primer lugar, numerosas fuentes bibliográficas analizan las características de la inserción externa de las empresas en un contexto de creciente globalización, dando lugar al enfoque de las cadenas globales de valor. ${ }^{2}$ Estos autores ponen el foco en la naturaleza de la relación entre los diversos actores involucrados en dicha cadena y en sus implicaciones para el desarrollo (Humphrey y Schmitz, 2002). Para ello, analizan las jerarquías que se establecen en la coordinación (governance) de los encadenamientos globales, su influencia en la distribución de beneficios y las posibilidades de upgrading (funcional, de producto, de proceso) que los diversos tipos de inserción exportadora puede permitir a empresas de países en desarrollo. Este trabajo no sólo analiza la naturaleza de la cadena, sino que determina cuáles son las limitaciones para su desarrollo y, en ese contexto, se incluye, también, como marco de análisis, la literatura sobre fallas de coordinación. Esta temática, lejos de ser nueva, fue abordada por Rosenstein-Rodan (1943 y 1957), Nurkse (1953 y 1961) y Hirschman (1958), quienes resaltaban las complementariedades existentes en las decisiones de inversión de los agentes, el papel de las economías de escala, la elasticidad de los factores y la transabilidad de los bienes o insumos. Recientemente, a partir del trabajo de Murphy, Shleifer y Vishny (1989), resurgió la problemática de las fallas de coordinación y la complementariedad estratégica como aspectos importantes al analizar las limitaciones al desarrollo industrial en algunos países. ${ }^{3}$

Otro enfoque es el (neo)institucionalista, el cual hace hincapié en el papel de las instituciones $^{4}$ al mediar en las interacciones de los agentes, condicionando su comportamiento

2 Véase, por ejemplo, Gereffi y Korzeniewicz (1994), Humphrey y Schmitz (2002), Kaplinsky, Morris y Readman (2001), IDs (1999). Para un análisis de los desafíos que las cadenas globales de valor plantean a los países en desarrollo, véase Bekerman y Cataife (2004).

3 Entre los trabajos recientes acerca del tema destacan los de Hoff (2000), Hoff y Stiglitz (2001), Krugman (1992), Ros (2000) y Rodrik (1994).

4 El término instituciones será entendido de las diferentes formas en que aparece en la literatura: reglas y normas de comportamiento que rigen la conducta de los agentes, hábitos de comportamiento de los agentes y organizaciones (agencias o entidades) que interactúan con los agentes.

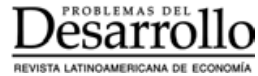


y el funcionamiento de la economía. Al romper con ciertos microfundamentos neoclásicos, la historia de las firmas y los aspectos económicos y no económicos que caracterizan a las instituciones pasan a constituir aspectos cruciales en la determinación del tipo de respuesta que generarán los agentes económicos. ${ }^{5}$

A esto se agregan los aportes evolucionistas que colocan en el centro de la escena el problema del cambio tecnológico, se enfocan en su naturaleza evolutiva y plantean una ruptura todavía mayor con los microfundamentos neoclásicos. De este modo, el comportamiento de los agentes no se halla bien representado por la conducta maximizadora, sino que puede ser mejor descrito en términos de rutinas, estrategias y procesos de búsqueda (Dosi et al., 1990). ${ }^{6}$ La relevancia de la interacción entre agentes e instituciones en la generación de procesos innovativos ha dado lugar a una visión sistémica de la innovación abordada por la literatura reciente. Surge el Sistema Nacional de Innovación, entendido como una red de instituciones cuyas interacciones determinan el desempeño innovativo de las empresas nacionales (Nelson y Rosenberg, 1993).

La vasta literatura existente acerca de clusters tradicionalmente ha puesto énfasis en las ventajas de la aglomeración — resumidas en el concepto eficiencia colectiva (Schmitz, 1995)_, enfocadas desde la perspectiva de los eslabonamientos productivos y la cooperación (más que desde el conocimiento, como lo hace la referida a sistemas de innovación) (Giuliani, 2003). De todos modos, hay un acuerdo creciente en la literatura reciente respecto de la importancia del conocimiento y el cambio tecnológico para interpretar la dinámica de los clusters (Rabellotti, 1997). Se subrayan, para el caso latinoamericano, los trabajos de Albaladejo (2001), Giuliani (2002 y 2003), Giuliani, Pietrobelli y Rabellotti (2003), Pietrobelli y Rabellotti (2003 y 2004), y Rabellotti (1993, 1997, 1999).

En el presente trabajo, las distintas vertientes teóricas señaladas se conjugan en un enfoque sistémico que abarca los planos microeconómicos (en el nivel de la firma), mesoeconómicos (sistemas de innovación y desarrollo de mercados) y macroeconómicos.

\section{El encadenamiento productivo de los muebles de madera y la segmentación del sector}

El encadenamiento productivo de los muebles de madera se inicia con la actividad forestal. Parte de los rollizos extraídos se destinan a la industria de la celulosa y el papel. El resto se distribuye a las fábricas de compensado, laminado y faqueado, y los aserraderos por un lado, y las fábricas de tableros, por el otro.

5 Se pueden mencionar, entre otros, Nelson y Sampat (2001), North (1996), Williamson (1985 y 2000).

6 Para una revisión de la literatura evolucionista, ver Dosi et al. (1988), López (1996), Nelson y Winter (1982).

\section{DeSarrollo}


La madera aserrada y secada se destinan a las industrias de remanufactura de la madera, a la industria de la construcción y la del mueble. Esta última incorpora también como insumos los distintos subproductos del procesamiento mecánico de la madera y los tableros y utiliza otros, entre los que sobresalen acabados, tapicería, abrasivos, adhesivos y herrajes.

La matriz de relaciones incluye la provisión de herramientas, maquinaria y equipo específico. Por último, se destacan las actividades de diseño y planificación logística (ya sea al interior de la empresa o por medio de terceros).

El encadenamiento se vincula con los distintos actores que participan en las actividades de distribución en los niveles nacional e internacional.

Respecto del sector de muebles, resulta relevante desde un punto de vista analítico realizar una diferencia por tipos en función de su gama, la cual se relaciona con una serie de aspectos productivos, entre ellos:

- Los muebles de gama baja son fundamentalmente lisos, con diseños simples, de líneas rectas y producidos principalmente en tableros.

- Los de gamas más altas incluyen detalles de terminación más sofisticados, incorporan mejores diseños, cuentan por lo general con una mayor proporción de madera maciza y de chapas de maderas de calidad.

Es importante subrayar que la maquinaria y el conocimiento en materia de diseño y trabajo calificado requeridos para los dos tipos de trabajo generalmente son diferentes, lo cual se refleja en el valor agregado y en importantes diferencias de precio (menores en muebles de gama baja). Por otro lado, ambas gamas plantean diferentes niveles de escala mínima eficiente, en la cual la de gama baja las economías de escala pesan más.

\section{El sector productor de muebles en el nivel internacional}

Comercio exterior: la inserción de los países en desarrollo y una creciente presión competitiva

A pesar de ser una industria tradicional, la producción mundial de muebles sigue concentrándose principalmente en los países desarrollados.

El comercio internacional de muebles de madera experimentó entre 1992 y 1999 un crecimiento menor (48\%) al del comercio mundial (57\%) y alcanzó en el último año 50 125 millones de dólares. En ese sentido, es el sector tradicional de baja tecnología el que registra mayor comercio internacional (Kaplinsky, 2000).

Los principales países exportadores son, en gran medida, desarrollados. No obstante, aparece un conjunto de países que han evidenciado una vertiginosa inserción internacional durante la última década. Entre ellos destacan los países asiáticos, y México y Brasil en Latinoamérica (Cuadro 1).

\section{Desarestrollo}


Cuadro 1

Principales exportadores de muebles de madera, 1992-1999 (millones de dólares)

\begin{tabular}{|c|c|c|c|c|c|c|c|}
\hline País & Dólares & $\begin{array}{c}1992 \\
\%\end{array}$ & Rank & Dólares & $\begin{array}{c}1999 \\
\%\end{array}$ & Rank & $\begin{array}{c}\text { Var. expo. } \\
\text { 1992-1999 } \\
\%\end{array}$ \\
\hline Italia & 3352336 & 20.6 & 1 & 3806564 & 15.8 & 1 & 13.5 \\
\hline China & 383930 & 2.4 & 13 & 2549920 & 10.6 & 2 & 564.2 \\
\hline Canadá & 384171 & 2.4 & 12 & 1955466 & 8.1 & 3 & 409.0 \\
\hline Alemania & 2337424 & 14.4 & 2 & 1916828 & 8.0 & 4 & -18.0 \\
\hline Polonia & 433874 & 2.7 & 10 & 1256195 & 5.2 & 5 & 189.5 \\
\hline Indonesia & 180088 & 1.1 & 19 & 1107410 & 4.6 & 6 & 514.9 \\
\hline Dinamarca & 1376611 & 8.5 & 3 & 1095973 & 4.5 & 7 & -20.4 \\
\hline Malasia & 202861 & 1.2 & 18 & 1027739 & 4.3 & 8 & 406.6 \\
\hline Francia & 656937 & 4.0 & 7 & 712937 & 3.0 & 9 & 8.5 \\
\hline Estados Unidos & 661505 & 4.1 & 6 & 703389 & 2.9 & 10 & 6.3 \\
\hline Taiwán & $\mathrm{s} / \mathrm{d}$ & & & 679170 & 2.8 & 11 & $\mathrm{~s} / \mathrm{d}$ \\
\hline Suecia & 468970 & 2.9 & 9 & 636496 & 2.6 & 12 & 35.7 \\
\hline Tailandia & 305277 & 1.9 & 16 & 608800 & 2.5 & 13 & 99.4 \\
\hline Bélgica & 902443 & 5.6 & 5 & 583319 & 2.4 & 14 & -35.4 \\
\hline México & 165343 & 1.0 & 20 & 568950 & 2.4 & 15 & 244.1 \\
\hline Brasil & 105767 & 0.7 & 24 & 323423 & 1.3 & 19 & 205.8 \\
\hline Argentina & 7352 & 0.0 & 47 & 11515 & 0.0 & 56 & 56.6 \\
\hline Total general & $16258 \quad 184$ & & & 24108478 & & & 48.3 \\
\hline
\end{tabular}

Fuente: elaboración propia con base en datos de International Trade Centre UNCTAD/wTO, United States Statistical Division, Base de Datos PC-TAS.

Se observa una caída de $34 \%$ del precio promedio de las exportaciones en el periodo analizado, que expresa distintos efectos. Por un lado, un efecto origen (el cual explica dos tercios de la disminución de precios), por la creciente participación de países en vías de desarrollo - con precios promedio menores - en un contexto de menores barreras a la entrada en la esfera productiva y de globalización de las cadenas de producción. Por otro lado, un efecto precio, que evidencia una disminución absoluta en los precios promedio y sólo puede asociarse a una mayor eficiencia productiva y de presión competitiva en el nivel global (explicando el resto de la caída).

Pero la brecha existente en cuanto a los precios promedio de exportación - en países desarrollados y en desarrollo — se redujo a lo largo de la última década (de 75.5\% en 1992 a $43.4 \%$ en 1999), lo que podría estar reflejando un proceso de upgrading en términos de diseño y calidad en las exportaciones de ciertos países en vías de desarrollo hacia muebles de mayor valor agregado.

En ese contexto pueden observarse situaciones diferenciadas entre los países en desarrollo. Sobresale el caso de Polonia, que logró incrementar el precio promedio de sus ventas externas de muebles de madera, con un aumento significativo en las cantidades y valores exportados. Esto podría ser un indicio de un upgrading de producto hacia un mueble de mayor valor agregado. Similar es el caso de Indonesia y Tailandia, que si bien 
Cuadro 2

Precio promedio de exportaciones de muebles de madera, por región económica, años 1992 y 1999 (dólares por kilo)

\begin{tabular}{lccc}
\hline & $\begin{array}{c}1992 \\
\text { US\$/kg }\end{array}$ & $\begin{array}{c}1999 \\
\text { US\$/kg }\end{array}$ & $\begin{array}{c}\text { Var } \\
1992-1999\end{array}$ \\
\hline Economías desarrolladas $^{\mathrm{a}}$ & 5.60 & 3.59 & $-35.7 \%$ \\
Unión Europea $_{\text {Asia (sin Japón) }}$ & 5.68 & 3.55 & $-37.5 \%$ \\
Economías en desarrollo $^{\mathrm{b}}$ & 3.16 & 2.59 & $-22.9 \%$ \\
\hline Total mundial $^{\mathrm{c}}$ & 3.00 & 2.53 & $-21.3 \%$ \\
\hline
\end{tabular}

a Se consideran economías desarrolladas: Alemania, Australia, Austria, Bélgica, Canadá, Dinamarca, El Salvador, Eslovenia, España, Estados Unidos, Finlandia, Francia, Grecia, Holanda, Irlanda, Islandia, Israel, Italia, Japón, Malta, Noruega, Nueva Zelanda, Portugal, Reino Unido, Suecia, Suiza, y la Unión Aduanera Sudraficana.

b Se consideran economías en desarrollo: Algeria, Arabia Saudita, Argentina, Armenia, Azerbaiján, Bangladesh, Barbados, Benin, Bolivia, Brasil, Brunei, Colombia, Costar Rica, Chile, China, Croacia, Cyprus, Dominica, Ecuador, Egipto, Filipinas, Ghana, Guatemala, Honduras, Hong Kong, India, Indonesia, Jordania, Kenya, Kuwait, Kyrgyzstán, Macau, Madagascar, Malasia, Mauricio, México, Nepal, Nicaragua, Níger, Nigeria, Omán, Pakistán, Panamá, Paraguay, Perú, República de Corea, Senegal, Singapur, Sri Lanka, Sudán, Tanzania, Tailandia, Togo, Trinidad y Tobago, Túnez, Turquía, Uganda, Uruguay, Venezuela, Yugoslavia, Zimbabwe.

c El precio promedio mundial es diferente al promedio de los precios de las economías desarrolladas y en desarrollo, ya que en el primero se consideran países que no entran en ninguna de las dos últimas categorías.

Fuente: elaboración propia con base en datos de International Trade Center UnCTAD/wTo, United States Statistical Division, Base de Datos PC-TAS.

experimentaron una caída en los precios de exportación, ésta fue sensiblemente inferior a la media mundial. Por el contrario, México y Brasil evidencian un crecimiento significativo en el comercio internacional, pero a costa de una caída en sus precios de exportación mayores a la media.

\section{Dinámica reciente del mercado mundial de muebles y su encadenamiento productivo}

La industria de muebles — caracterizada en el nivel mundial por estar relativamente poco concentrada y por el predominio de PYMES ${ }^{7}$ experimentó en los últimos años notables transformaciones en sus patrones tecnológicos, de organización y de comercio exterior. En el área productiva, sobresale la introducción de equipo automatizado (maquinaria a control numérico), el cual generó un fuerte aumento de la productividad física que mantiene altos grados de flexibilidad y una reducción/cambio en la naturaleza de las calificaciones laborales requeridas. Se ha verificado, también, un creciente uso de nuevas materias

$7 \quad$ Este fenómeno se relaciona con la fuerte variabilidad de la demanda, la importancia de las innovaciones de diseño y un papel de las economías de escala en la producción menos significativo que en otras industrias.

\section{DeSarrollo}


primas, entre las que desatacan los tableros de media densidad y las maderas reforestadas, lo cual otorga ventajas comparativas a las regiones más aptas para la forestación (Gorini, 2000).

Las transformaciones estructurales del sector no han sido menos importantes en el área de la organización de la producción y el comercio internacional. En este sentido, aunque con grandes diferencias entre los distintos países desarrollados, se confirma una tendencia a la concentración de las ventas de muebles de gama baja y media en grandes cadenas especializadas (por ejemplo, ready-to-assemble y do-it-yourself), como la sueca IKEA o la británica B\&Q. Éstas, a su vez, monopolizan ciertos canales de comercialización y se aprovisionan con cientos de proveedores esparcidos por todo el mundo, quienes ven limitada su participación casi exclusivamente a las actividades vinculadas con la espera productiva, generalmente con altos niveles de estandarización (Kaplinsky et al., 2001; Kaplinsky, 2000).

Estos cambios en la comercialización y la creciente importancia de los diseños innovadores han generado nuevas barreras a la entrada, que impiden a fabricantes de países en desarrollo dominar las principales actividades generadoras de renta dentro del encadenamiento (logística, comercialización y diseño). De esta manera, la cadena global de los muebles de madera avanza, en términos generales, hacia el tipo de encadenamiento productivo denominado "cautivo" (Gereffi, Humphrey y Sturgeon, 2003) y, dentro del mismo, hacia la modalidad conocida como "liderada por el comprador" (Gereffi y Korzeniewicz, 1994; IDS, 1999; Kaplinsky y Readman, 2000; Kaplinsky, Morris y Readman, 2001), caracterizada por una elevada complejidad de las transacciones, cierta capacidad para codificación de las mismas (en este caso, por medio de planos con los diseños y especificaciones técnicas de los materiales) y bajas capacidades de la oferta (Gereffi, Humphrey y Sturgeon, 2003). Estas últimas se asocian, básicamente, con las barreras de entrada en materia de capacidad de diseño, logística, marketing y comercialización, que ubican en situación de dependencia a los pequeños productores industriales (fundamentalmente los alejados de los principales centros de consumo).

Los líderes de la cadena fijan las condiciones que deben cumplir las empresas que forman parte de la red de proveedores, entre las cuales destacan las exigencias de estándares (de calidad, ambientales, laborales, por mencionar algunos), lo que conforma un nuevo tipo de barreras a la entrada (Kaplinsky, Morris y Readman, 2001). El desarrollo de esta modalidad de organización mundial de la producción y comercialización de muebles ha tenido un alto impacto, aunque diverso, en la evolución de actividades productivas y de comercio exterior en los países menos desarrollados. La transferencia de tecnologías de producto y de proceso, así como la solución ofrecida en materia de logística y comercialización permite el desarrollo de importantes capacidades productivas y de procesos de aprendizaje. A su vez, la inserción en encadenamientos globales cautivos limita, en muchos casos, la incorporación y desarrollo de capacidades en áreas donde priman las barreras a la entrada (las más rentables del encadenamiento).

\section{DeSarrollo}


En este sentido, Kaplinsky et al. (2001) enfatizan el riesgo de que, a partir de una incorporación adversa ligada al no cumplimiento de estándares laborales o ambientales, se alcance un crecimiento empobrecedor. Esta hipótesis adquiere particular relevancia para todas aquellas relaciones directas fundadas en la tercerización de actividades muy estandarizadas y en las cuales costos y riesgos recaen, principalmente, en la empresa subcontratista.

\section{El encadenamiento productivo del mueble en Argentina}

\section{Aspectos generales del sector: estructura, producción y comercio exterior}

La industria argentina del mueble se caracteriza por la presencia de numerosas micro, pequeñas y medianas empresas; las más grandes no superan, en general, los cien empleados.

Las empresas dedicadas a la primera industrialización de la madera, junto con las industrias del laminado, se localizan en gran medida en torno de complejos foresto-industriales regionales, mientras que la industria del mueble de madera se concentra fundamentalmente cerca de las principales áreas metropolitanas y alrededor de los polos productivos regionales.

La producción tuvo su pico en 1998, para luego desplomarse hasta alcanzar en 2002 un valor equivalente a $41 \%$ del registrado en $1993 .{ }^{8}$ Los precios del sector muestran, a su vez, un comportamiento procíclico con un incremento entre 1993 y 1998, y una fuerte caída entre 1998 y 2001.

Durante la última década, el conjunto muebles y partes de madera muestra niveles de exportación estables y bastante modestos (1.8\% del vBP sectorial en 2001). Como principal destino tiende a consolidarse Estados Unidos (60\% del total de exportaciones en 2001), a donde se envían generalmente muebles de gama media o media alta de madera maciza.

Después de la devaluación se produjo una serie de transformaciones en el modelo de exportaciones del encadenamiento. Las exportaciones de muebles experimentaron un crecimiento muy moderado mientras que el resto del encadenamiento mostró uno fuerte. En 2002, las ventas efectuadas a Estados Unidos (de muebles de mayor valor agregado) cayeron en términos absolutos, mientras que las dirigidas a Chile, constituidas fundamentalmente por muebles de gama baja, crecieron fuertemente (de 5\% de las exportaciones argentinas en 2001 a $33 \%$ en 2002). ${ }^{9}$

Esto parece confirmar que la competitividad estructural de Argentina en el sector está vinculada con los muebles de gama media y alta de madera maciza; mientras que los de

8 No existen estadísticas adecuadas que permitan reflejar la evolución de la producción de muebles de madera. Por ello, se recurre a la serie de volumen físico y de precios mayoristas del sector en su conjunto (que incluye colchones y muebles de otros materiales) de la Encuesta Industrial Anual que realiza el INDEC para actualizar los valores censales.

$9 \quad$ Este crecimiento fue protagonizado por un reducido conjunto de empresas (principalmente Cuyoplacas y Maderpack) que no tienen experiencia exportadora previa de importancia. Si no fuera por el incremento de las exportaciones a Chile, las totales de muebles de madera hubieran caído más de $20 \%$.

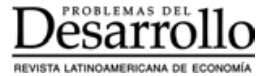


MARTA BEKERMAN, SANTIAGO RODRÍGUEZY PABLO SIRLIN

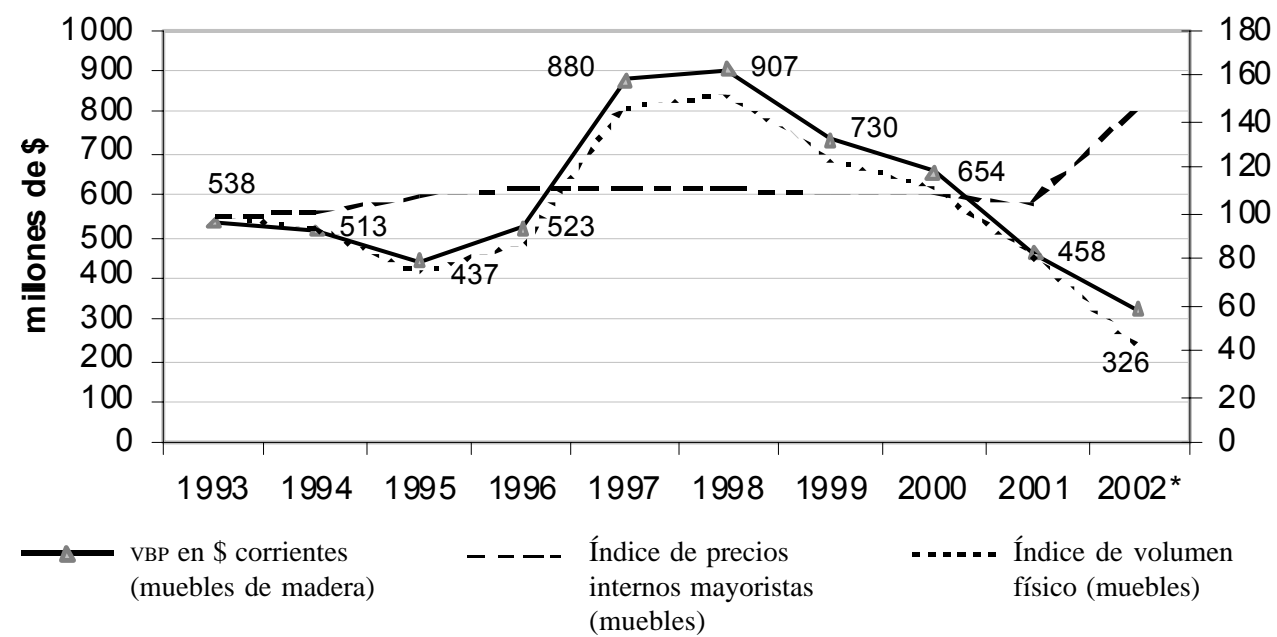

Gráfica 1. Producción corriente de muebles de madera (en millones de pesos), índice de voumen físico e índice de precios mayoristas de muebles.

* La cotización promedio del dólar para el año 2002 fue de 3.1 pesos = 1dólar. Para el resto de los años fue peso $=1$ dólar.

Fuente: elaboración propia con datos del INDEC.

gama baja, fabricados con tableros, tienen una inserción mucho más reciente y basada en un tipo de cambio real muy alto (probablemente, insostenible en el tiempo).

También indica que la sola mejora del tipo de cambio resulta insuficiente, al menos en el corto plazo, para impulsar las exportaciones de muebles de gama alta, cuya inserción internacional resulta más dependiente de otros aspectos relevantes como diseño, calidad de terminación y desarrollo de redes de comercialización adecuadas.

Las importaciones de muebles de madera crecieron significativamente en los años noventa, constituyéndose como el eslabón de mayor peso en las importaciones del encadenamiento. Éstas tienen su origen principalmente en Brasil (cerca de $60 \%$ en promedio en los últimos cinco años) de donde se importaron muebles de tableros de gama baja. En segundo lugar aparecen las importaciones desde los países europeos (principalmente Italia), de donde provienen los muebles de gama más alta (alrededor de $20 \%$ en los últimos cinco años), pero con la recesión, las importaciones cayeron en 2001 y colapsaron en 2002 (-95\%).

Hasta 2001, el encadenamiento tuvo una balanza comercial permanentemente negativa, que sólo se revirtió con posterioridad a la devaluación del peso y como resultado del virtual colapso de las importaciones (los únicos rubros que muestran un superávit sistemático son rollizos y tableros). En cambio, el principal rubro deficitario es el sector de muebles de madera, que evidencia un modelo de especialización con claras debilidades en el segmento de mayor valor agregado del encadenamiento.

\section{DeSarrollo}




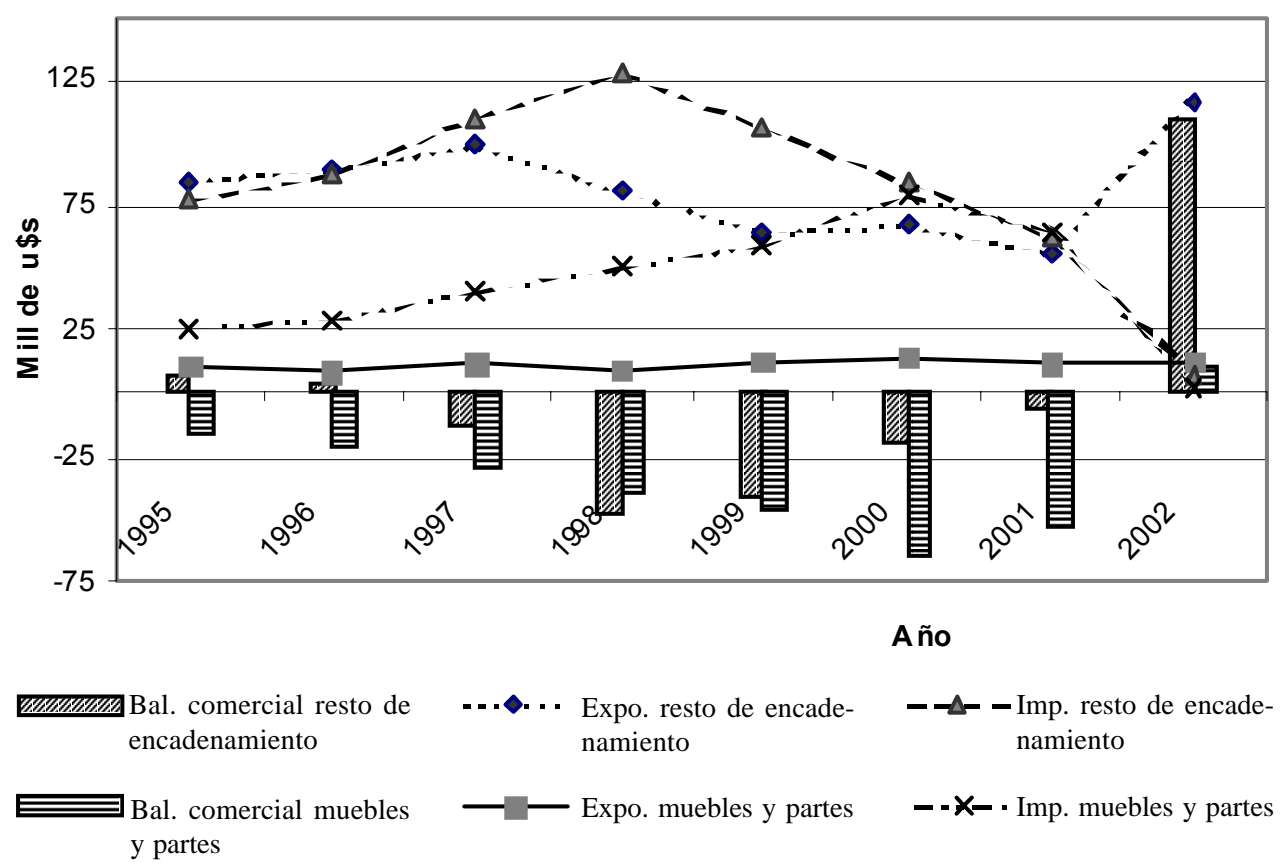

Gráfica 2. Comercio exterior del encadenamiento productivo, en millones de dólares.

Fuente: elaboración propia con datos del INDEC.

Tendencias recientes del sector fabricante de muebles de madera. Ganadores y perdedores ${ }^{10}$

En la década de los noventa el sector de muebles de madera creció, aunque de manera heterogénea, con base en el fuerte incremento en la demanda interna generado por el boom de la construcción y la expansión del crédito al consumo, ciclo que se cortó drásticamente en 1998. La crisis impactó de diversas formas al sector; se produjo el cierre de un numeroso conjunto de establecimientos - cuya magnitud es imposible determinar con precisión — ${ }^{11}$ y una reducción en la facturación, que llega a un promedio de $50 \%$ entre 1998 y 2002, aunque mostrando fuertes diferencias entre las compañías entrevistadas.

Las empresas relativamente más grandes experimentaron una menor caída promedio en los niveles de producción (-22\%) que las más chicas (-57\%). Esta diferencia puede estar vinculada con la capacidad para amortiguar la caída en la demanda interna con las exportaciones. En particular, las que ya tenían alguna experiencia exportadora previa a

10 Las apreciaciones de este apartado y del siguiente se basan en un estudio de campo realizado entre mayo y agosto de 2003, descrito en el Anexo metodológico.

11 Datos de la Federación Argentina de la Industria del Mueble y Afines permiten estimar una caída en el número de establecimientos de $20 \%$ entre 1999 y 2001.

\section{Desararrollo}


2002 (en su mayoría empresas grandes) evidencian un nivel de actividad promedio constante (contra una disminución de 59\% del resto).

Desde un punto de vista sectorial, se aprecia que las empresas fabricantes de muebles de gama más baja experimentaron, en promedio, una caída superior (67\%) que las orientadas a gamas más altas (17\%). Ello se explicaría por el efecto disruptivo que tuvieron las importaciones brasileñas en 2000 y 2001 y el deterioro en la distribución del ingreso generado por la crisis. Combinando todos los resultados, tenemos que las grandes perdedoras fueron las empresas chicas, las no exportadoras y las especializadas en muebles de gama baja, cuya producción decreció, en los casos incluidos en nuestra muestra, en 90\%. En el otro extremo, las empresas más grandes, con experiencia exportadora y que no sufren competencia de Brasil experimentan en promedio un decremento más moderado (-20\%).

La caída en los niveles de producción impactó al sector directamente en el empleo (que entre 1998 y 2002 habría expulsado 6100 trabajadores), y sobre el grado de capacidad usada que, para el promedio de las empresas encuestadas, bajó de $73 \%$ a 40\%. El esfuerzo por sostener los niveles de venta implicó, asimismo, una casi generalizada disminución en los márgenes de rentabilidad sobre ventas, principalmente en las productoras de muebles de gama baja.

El cambio en los precios relativos promovió el reemplazo de insumos y maquinaria nacionales por importados, que redujeron los ya limitados niveles de subcontratación local y provocaron rupturas en la relación de las empresas con sus proveedores.

\section{Obstáculos al desarrollo de la competitividad del encadenamiento en Argentina}

Si bien la producción de muebles de madera cuenta con importantes ventajas comparativas (por la disponibilidad de materia prima) y una larga tradición productiva en el país, su desarrollo competitivo encuentra actualmente una serie de obstáculos que limitan su consolidación productiva y exportadora. Es posible identificar dos grandes conjuntos de factores limitantes: los que tienen que ver con debilidades tecnológicas, y los relacionados con la organización e institucionalidad del sector, ambos vinculados entre sí.

\section{El atraso tecnológico. El sistema nacional de innovación y la capacidad innovativa de las firmas}

A pesar de ser una industria tradicional, la brecha tecnológica es uno de los principales factores que limita la competitividad de las empresas productoras de muebles de los países en desarrollo. Se manifiesta, en gran medida, en la dificultad de esas naciones para dominar las etapas más rentables del encadenamiento productivo (notablemente el diseño, las tecnologías de acabado y la comercialización). En este sentido, el sector productor de

\section{DeSarrollo}




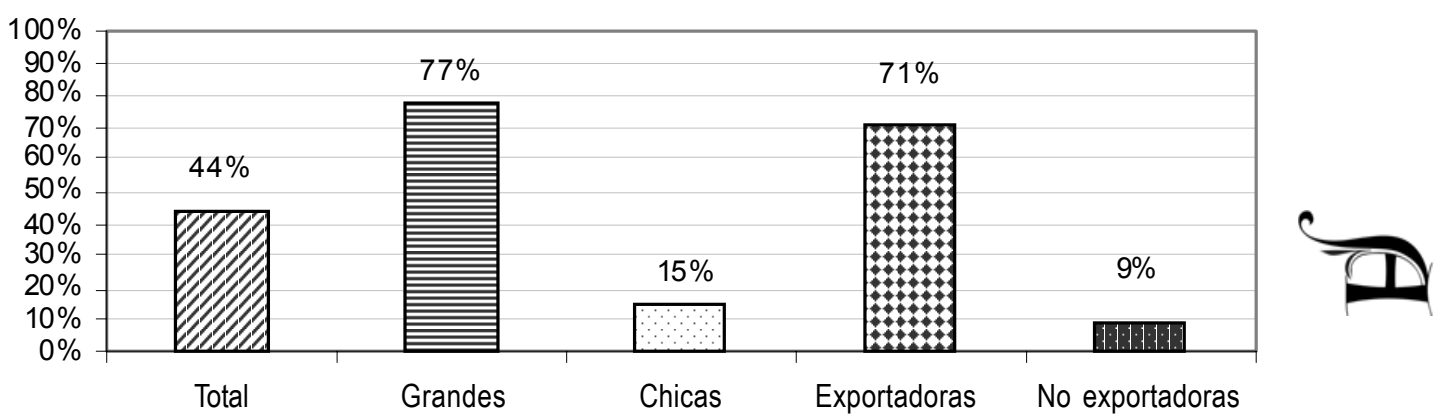

Gráfica 3. Empresas que cuentan con personal o departamento de diseño, por tipo de empresa.

Fuente: estudio de campo.

muebles de madera argentino muestra importantes carencias y una fuerte heterogeneidad en tecnología de producto, proceso y organización.

En materia de diseño (aspecto clave en cuanto a tecnología de producto), la industria nacional evidencia considerables debilidades, tanto en el nivel de las firmas individuales como en el del país, pues no existe un modelo de diseño propio. La mayor parte de las empresas del sector trabaja sobre la base de una copia o adaptación deficiente, que desvirtúa los diseños originales y les hace perder valor. Asimismo, su profesionalización se encuentra muy poco difundida al interior de las firmas y se limita, casi exclusivamente, a las empresas exportadoras y a las más grandes (de más de 40 empleados). En este sentido, sólo 44\% de las empresas entrevistadas declaró contar con personal capacitado en materia de diseño. ${ }^{12}$

Las empresas que han logrado exportar (55\% de la muestra) $)^{13}$ tienden a reproducir las características ya mencionadas de los encadenamientos cautivos (aunque en niveles de escala sensiblemente inferiores): el diseño del producto es suministrado habitualmente por el cliente en el exterior, quien a su vez mantiene un completo control de los canales de comercialización (93\% de los casos).

En cuanto a la organización, se observa bajo uso de tecnologías modernas de gestión, limitado exclusivamente a las empresas grandes. En este sentido, solamente 16\% de las empresas entrevistadas (todas grandes) declararon haber certificado normas de calidad ISO-9000.

La innovación en tecnología de proceso se caracteriza también por su heterogeneidad, en la cual sobresalen las empresas más grandes y productoras de muebles de madera maciza por haber incorporado maquinaria de última generación en años recientes, a la luz de un tipo de cambio atrasado. Así, del total de empresas grandes encuestadas, $85 \%$ tenía

12 Este hecho contrasta con lo revelado en un estudio de campo realizado en trece empresas de los dos principales polos exportadores de Brasil, ya que todas declararon contar con profesionales en esa área. No obstante, las capacidades en las empresas brasileñas exportadoras tienden a limitarse a las necesarias para recibir, adaptar y desarrollar los diseños aportados por los clientes externos.

13 Se debe tener en cuenta que la muestra seleccionada presenta un sesgo hacia las empresas exportadoras (véase Anexo metodológico).

\section{DeSarrollo}


acceso a este tipo de tecnología. Al mismo tiempo, del total que usaba tecnología automática, $73 \%$ eran grandes.

En el escaso desarrollo de la capacidad innovativa de las empresas del sector intervienen diversos factores, ubicados en los planos macro, meso y microeconómico, y se condicionan e influyen mutuamente. En el nivel macroeconómico, el primer factor por mencionar lo constituye el tradicional sesgo antiexportador que afectó al sector en el periodo sustitutivo de importaciones y que llevó a una excesiva orientación mercadointernista de la industria, en general, y de la producción doméstica de muebles de madera, en particular. Asimismo, generó una apertura excesiva del mix de producción, debido a la rentabilidad diferencial que presentaba el mercado interno frente al de exportación, lo que afectó negativamente la especialización horizontal de las empresas del sector. La ausencia de competencia externa y la existencia de un mercado poco exigente y de escaso poder adquisitivo, limitaron el disciplinamiento que asegura la competencia y no generaron los incentivos que podrían haber llevado al sector a mejorar los estándares de diseño y calidad de sus productos. ${ }^{14}$

Por su parte, la continua inestabilidad macroeconómica ha conducido, en general, a acortar los horizontes de planeamiento, en detrimento de inversiones que requieren mayor plazo de maduración, como las que caracterizan a la innovación tecnológica. La inestabilidad del tipo de cambio real también desincentivó inversiones en tecnologías de producto que sólo podrían haberse amortizado mediante una inserción sistemática en los mercados internacionales. Por último, la fuerte inestabilidad de la demanda potenció la excesiva diversificación horizontal de las firmas del sector, en especial como estrategia defensiva en los periodos recesivos.

Desde una perspectiva microeconómica, se trata de un sector compuesto por un conjunto vasto de micro y pequeñas empresas, las cuales han surgido, por lo general, sobre la base de pequeños talleres de artesanos. Así, en numerosos casos, los artesanos-empresarios carecen del umbral mínimo de capacidades y competencias (de gestión, educativa, emprendedora) necesarias para la generación de procesos innovativos o tienen niveles de producción insuficientes para amortizar inversiones grandes en nuevas tecnologías. Es más, su incorporación (especialmente de producto y organización) puede no ser vista habitualmente como un potencial factor de competitividad, sino como un gasto innecesario. En este sentido, de las empresas entrevistadas, $40 \%$ declaró no contar con ningún profesional en su plantel de empleados (incluyendo a los dueños de las empresas).

La influencia generada por el ambiente local o nacional en la capacidad innovativa de las firmas se relaciona, en parte, con la imperfecta transabilidad del conocimiento, lo que limita el libre acceso a determinadas tecnologías. Es por ello que la inserción exportadora

14 El papel que juegan las características de la demanda interna y el ambiente competitivo en la capacidad innovativa de las firmas puede verse, por ejemplo, en Porter (1990).

\section{DeSarrollo}


(mediante contactos con clientes extranjeros) cobra vital importancia como fuente de transferencia tecnológica hacia empresas y sistemas locales. ${ }^{15}$

De acuerdo con nuestro estudio de campo, la interacción con los clientes internacionales involucra un importante intercambio de información en lo que se refiere a diseños y técnicas de acabado. El total de las empresas exportadoras entrevistadas que comercializan sus productos más allá de los países limítrofes declararon que el diseño es provisto generalmente por el cliente, con quien se mantiene un asiduo intercambio de información. Esto ha dado lugar a procesos dinámicos de aprendizaje que han propiciado un incremento en las capacidades de las firmas locales exportadoras, lo cual se manifesta también en una fuerte heterogeneidad en cuanto a las capacidades de diseño de las empresas, dependiendo si son exportadoras o no (véase Gráfica 3).

La capacidad innovativa y el desempeño de las firmas se ven condicionados, a su vez, por el ambiente en el que éstas se desenvuelven, debido a la actuación de elementos ubicados en el plano mesoeconómico, entre los cuales sobresale el bajo grado de desarrollo del Sistema Nacional de Innovación. A partir de nuestro estudio de campo se observa, en general, una baja vinculación entre empresas y un escaso desarrollo de instituciones afines al sector, siendo la interacción con estas últimas muy débil. En relación con las fallas de coordinación que se plantean en el siguiente apartado, se observa un reducido intercambio de información (ya sea por canales formales o informales) entre empresas competidoras, con sus proveedores o clientes locales. En el caso de la materia prima, el intercambio de información se ve dificultado porque parte de los insumos críticos (como los acabados) son de importación. Asimismo, la fuerte situación de deterioro en la que se hallan las cámaras sectoriales (signada, entre otras cosas, por una fuerte disminución de socios) propicia un significativo obstáculo al fluir de información entre las empresas del sector. ${ }^{16}$

Por otro lado, la relación con el sistema educativo es prácticamente nula, mientras que en lo referente a las instituciones públicas cuya función es brindar información técnica o comercial (INTI, Cancillería, Fundación Exportar, CFI, Centro Metropolitano del Diseño), si bien $41 \%$ de las empresas entrevistadas declara haber tenido algún tipo de contacto, se trata de relaciones muy esporádicas y con experiencias no siempre positivas. ${ }^{17}$

15 Esto se pone de relieve especialmente en el caso del sector de muebles brasileño. En este sentido, solamente los polos exportadores de São Bento do Sul y Bento Gonçalves han alcanzado adecuados estándares de calidad y diseño, y niveles de competitividad internacionales, lo que contrasta con la situación del resto de la industria brasileña de muebles (Ferraz y Nassar, 2002).

16 Se observa también una diferencia significativa respecto de los polos brasileños mencionados; en ellos hay mayor desarrollo de instituciones afines al sector y destacan las interacciones con centros tecnológicos y universidades, así como una alta representatividad institucional de las cámaras que tienen, a su vez, un papel importante en la difusión y coejecución de los programas nacionales o estaduales dirigidos al sector.

17 Los principales problemas mencionados se relacionan con tiempos de respuesta muy prolongados, falta de capacidades técnicas o carencias en la organización de actividades y en la información suministrada.

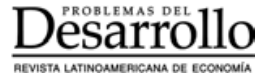


Se observa un mayor desarrollo del sistema de innovación en el nivel local, en el caso de los polos muebleros regionales, especialmente en Esperanza. Sobresale la existencia de mayores vínculos entre empresas y con instituciones del entorno (registrándose también un mayor desarrollo de éstas), lo que da cuenta de las ventajas derivadas de la aglomeración geográfica de empresas. Sin embargo, las relaciones son débiles, distando considerablemente de las observadas en otras experiencias internacionales, por ejemplo en el caso de los distritos industriales italianos o, incluso, en los polos productivos brasileros.

Se debe destacar que un débil Sistema Nacional de Innovación no impide, pero sí limita seriamente, la capacidad innovativa y el desempeño de las firmas, especialmente en sectores con estructuras productivas basadas en PYMES. De este modo, si bien empresas productoras de muebles que han alcanzado adecuados estándares tecnológicos y de competitividad, estos casos son pocos y están basados, principalmente, en características microeconómicas excepcionales cuya aplicación suele limitarse a las empresas de mayor tamaño. ${ }^{18}$

\section{Desarrollo de mercados y fallas de coordinación}

Escaso desarrollo de mercados críticos

y falta de proveedores especializados

El escaso desarrollo de ciertos mercados críticos limita, en forma considerable el desarrollo de la industria productora de muebles de madera. Las fallas de coordinación y la considerable debilidad institucional (formal e informal) son los principales factores limitantes.

El diseño constituye un mercado de relevancia para el impulso de un sector de muebles dinámico y competitivo, pero se encuentra poco desarrollado, lo cual manifiesta una fuerte descoordinación entre diseño e industria. Esto se da en un contexto de instituciones públicas débiles que apuntan a resolver esas fallas. Si bien algunas instituciones formales protegen la propiedad intelectual de los diseños, el Estado no posee el enforcement necesario para hacer cumplir las normas, y no existen instituciones informales que cubran esta función. De este modo, la copia tiende a generalizarse, lo cual desincentiva a las empresas productoras de muebles a invertir en esa actividad y a los diseñadores a acercarse a las empresas para ofrecer sus servicios. Este aspecto fue mencionado como problema relevante por $70 \%$ de las empresas entrevistadas, las cuales reconocieron que los diseños de sus productos copiados o adaptados de otros existentes en el mercado.

La provisión de madera de calidad, con las especificaciones requeridas, constituye un aspecto crítico para el sector de muebles, especialmente de madera maciza. El mercado argentino de la madera presenta graves falencias entre las que destacan: a) alta presencia

18 En este sentido, consideramos como ejemplos válidos las experiencias de Fontenla (muebles clásicos de alta gama), Dadone y Cravero (de pino de gama media), y Giuliani (de oficina), Mehring (en sillas) e IVOPE (de algarrobo).

\section{DeSarrollo}


de nudos, $b$ ) fuerte déficit de maderas de mayor valor para muebles de gamas más altas, c) fuerte déficit en materia de capacidad y calidad del secado y $d$ ) inadecuada clasificación de la madera maciza según su calidad. Dentro de las causas de estas deficiencias sobresalen diversas fallas de mercado y de coordinación (derivadas en una subinversión en tecnología por parte de los proveedores del sector), y bajo desarrollo institucional, lo cual genera elevados costos de transacción.

Resaltan, también, las fallas de coordinación en las decisiones de inversión entre productores de muebles y proveedores de madera. En este sentido, la ausencia de materia prima de calidad limita el desarrollo del sector de muebles de gama alta, lo que impide, a su vez, el surgimiento de proveedores especializados.

El bajo desarrollo institucional se manifiesta, además, en la ausencia de instituciones que establezcan normas de clasificación de la madera y promuevan la coordinación entre los agentes, para disminuir los costos de transacción prevalecientes y condicionar un desarrollo consistente del mercado.

En virtud de estos problemas, los productores han adoptado diversas estrategias que, si bien dada la matriz tecnológica e institucional actual representan soluciones para la empresa individual, habitualmente limitan el desarrollo del encadenamiento en su conjunto, sobre todo, subrayamos, la integración vertical de la etapa de secado en las empresas más grandes ${ }^{19} \mathrm{y}$, en pocos casos, de la producción forestal misma. Estas empresas -incluso a costa de disminuir su grado de especialización y de mantener parte de su capacidad ociosa - optan por integrarse verticalmente, lo cual ilustra la magnitud de los costos de transacción involucrados. Al mismo tiempo, al ser los principales consumidores de madera de calidad, limitan la expansión de la demanda de esta materia prima, restringiendo el desarrollo de proveedores especializados. ${ }^{20}$

El mercado del acabado constituye un aspecto crítico para la industria del mueble de madera maciza; en Argentina se observa una ausencia considerable de proveedores especializados en este tipo de materiales. Nuevamente, el escaso desarrollo de un sector de muebles de gama alta, con adecuados estándares de calidad, demandante de este tipo de insumos, limita el desarrollo (o la radicación) de una industria competitiva de materiales para el acabado y la ausencia de estos proveedores condiciona, a su vez, el desarrollo de la industria del mueble. La falla de coordinación existente no logra resolverse con la importación de estos productos, debido a que una parte considerable de las innovaciones en tecnología de acabados se obtiene por medio de un continuo intercambio de información técnica entre

19 Como son los casos de las empresas Fontenla, Cravero, HDH, MBM e IVOPE.

20 El bajo desarrollo del mercado de la madera presenta características similares en la industria de muebles brasileña, incluso en el caso de las empresas ubicadas en los polos productivos que muestran niveles más altos de competitividad. Las estrategias adoptadas son también similares, aunque dada la mayor capacidad financiera media de las firmas brasileñas, los niveles de integración vertical alcanzados son, en general, mejores que los observados para las empresas argentinas. 
productores de muebles y proveedores de materiales para lustre, lo cual se dificulta por las distancias geográfica y cultural.

Por tratarse de un sector primordialmente integrado por PYME, un mercado de especial relevancia es el de partes y piezas, posible de ser subcontratado. Un mayor desarrollo de las prácticas de subcontratación permitirían alcanzar mayor grado de especialización vertical, e incrementaría los niveles de eficiencia del sector. Sin embargo, sólo $32 \%$ de las empresas entrevistadas declara trabajar sistemáticamente con subcontratistas, tercerizando $15 \%$ o más de su producción. El bajo desarrollo de las prácticas de subcontratación durante los noventa condujo no sólo a menores niveles de productividad, sino también a un sobreequipamiento generalizado en maquinaria no especializada.

Uno de los principales objetivos de la subcontratación es alcanzar mayores niveles de flexibilidad, o sea, mayor capacidad de ajuste a los cambios de demanda, y menores costos de incorporación y desincorporación de trabajadores. Esto deja de manifiesto la ausencia de estrategias empresariales dirigidas a la formación y seguimiento de proveedores.

Entre los principales obstáculos para el desarrollo de este mercado se encuentra la fuerte inestabilidad macroeconómica, que incrementa los costos de transacción inherentes a las relaciones de subcontratación y favorece una baja capacidad en la base de la oferta (aspecto que se refleja en diversas experiencias infructuosas).

Sin embargo, el desarrollo del mercado de subcontratación es mayor en el caso de empresas ubicadas en los polos muebleros de Cañada de Gómez y Esperanza, que elevan $50 \%$ el porcentaje mencionado. Este hecho da la pauta de que la existencia de una oferta mayor y más variada de empresas y talleres especializados y su cercanía geográfica permiten la reducción de los costos de transacción implícitos en el establecimiento de relaciones de subcontratación.

\section{Relaciones asociativas entre empresas}

$\mathrm{Al}$ tratarse de un sector con una estructura productiva basada en micro, pequeñas y medianas empresas, el desarrollo de relaciones asociativas entre ellas - consciously pursued joint action, en términos de Schmitz (1999) — tienen un papel preponderante por diversas razones. Por un lado, permite enfrentar las limitaciones que surgen como resultado de altos costos fijos e indivisibilidades presentes en ciertas actividades clave para el desarrollo competitivo de las firmas, de manera especial en la comercialización (principalmente externa) y el diseño. En este sentido, de acuerdo con nuestro estudio de campo, el tamaño de la empresa se muestra como variable relevante, tanto en la determinación de la orientación exportadora, como por el hecho de contar con un área especializada en diseño; entre las empresas que exportan, $73 \%$ son relativamente grandes (más de 40 empleados). Asimismo, son éstas las que cuentan, mayoritariamente, con diseñadores.

\section{DeSarrollo}


Resulta sumamente significativo que de las tres empresas chicas con orientación exportadora relevadas, dos forman parte de un consorcio exportador. Lo mismo ocurre con las empresas pequeñas que cuentan con personal dedicado al diseño, porque todas lo comparten en el contexto de un consorcio. De este modo, las prácticas asociativas parecen haber sido un factor fundamental para alcanzar la escala requerida para desarrollar con éxito procesos de comercialización y diseño, pues permitieron a las empresas pequeñas saltar la barrera del tamaño y lograr una inserción exportadora.

Por otro lado, el desarrollo de iniciativas asociativas brinda la posibilidad de desarrollar esquemas de especialización productiva y alcanzar mayores niveles de eficiencia. No obstante, en el sector de muebles argentino estas iniciativas asociativas se limitan habitualmente a aspectos comerciales (comercialización externa, o pool de compras), siendo excepcionales los esquemas de complementación productiva.

A pesar de la relevancia y la potencialidad que encierran para el desarrollo del encadenamiento, las acciones asociativas entre empresas se encuentran muy poco difundidas. Se han detectado solamente ocho en cuanto a cooperación interempresaria en productoras de muebles: seis consorcios de exportación y dos clubes de compras. La mayor parte de las experiencias relevadas corresponden a empresas situadas en los polos productivos regionales, lo cual evidencia la importancia de la concentración geográfica en las pautas de interacción interempresarias.

Sin embargo, pueden apreciarse dos trayectorias diferenciadas. En Cañada de Gómez se observa un alto porcentaje de experiencias fracasadas que demuestra ausencia de niveles importantes de capital social, a pesar de la concentración geográfica. De acuerdo con empresarios entrevistados, los principales limitantes para avanzar en proyectos de naturaleza asociativa son las trabas culturales, el individualismo, entre otros. Por el contrario, entrevistas realizadas en Esperanza permitieron detectar mayor nivel de asociación, en el cual destaca un consorcio de fabricantes de muebles de madera (Quadra). ${ }^{21}$

Se detectaron únicamente dos iniciativas fuera de los polos productivos regionales, pero muestran una menor intensidad asociativa y resultados muy limitados.

\section{Evaluación general y recomendaciones de política}

\section{Evaluación general}

A partir del estudio realizado, podemos afirmar que el sector de muebles de madera y su encadenamiento en Argentina está predominantemente integrado por PYME. Se concentra, fundamentalmente, en Capital Federal y Gran Buenos Aires, así como en algunos polos muebleros en la provincia de Santa Fe (Cañada de Gómez y Esperanza), con concentraciones

21 Éste se caracteriza por: a) diseñadores comunes, b) desarrollo de una línea de productos, con un esquema de especialización productiva, c) esfuerzos de comercialización comunes.

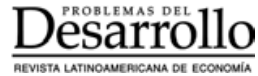


menores en Córdoba, Mendoza, Chaco, Formosa y Entre Ríos. En los polos productivos regionales, a pesar de la concentración geográfica, son limitadas las interacciones estratégicas de las firmas en comparación con casos paradigmáticos, como los distritos industriales italianos. El sector está orientado esencialmente hacia el mercado interno, presenta un carácter estructuralmente deficitario y muestra un modelo de especialización sesgado en contra del segmento de mayor valor agregado dentro del encadenamiento (los muebles).

Por otro lado, puede observarse una estructura de mercado basada en:

- Un conjunto de empresas, en su mayoría pequeñas, que fabrican muebles sin diseño incorporado (con problemas de acabado y calidad), dirigidos exclusivamente al mercado interno.

- Empresas relativamente grandes y equipadas que fabrican muebles de tableros de gama baja y media, comercializados en gran medida mediante el canal hipermercadista y exportados a países limítrofes.

- Empresas pequeñas, medianas y grandes con tecnología de producto (ya sea propia o transferida por clientes internacionales) que fabrican en su mayoría muebles de madera maciza para exportación y para el mercado interno más exigente.

Si bien se trata de un encadenamiento con un alto potencial de desarrollo (fundamentado en las ventajas naturales asociadas y en una larga tradición productiva), adolece de debilidades competitivas derivadas de problemas de índole tecnológica e institucional. Las empresas muestran un importante rezago en materia de tecnologías de producto (diseño y acabados), siendo poco frecuente la existencia de áreas específicas de diseño y habitual la copia de los mismos. Pocas firmas (principalmente grandes y exportadoras) han alcanzado adecuados estándares de diseño y acabado. Por otro lado, se observa una muy baja difusión de las tecnologías modernas de gestión, limitada exclusivamente a las compañías más grandes, y una situación muy heterogénea en lo que respecta a tecnologías de proceso.

Como fuente del rezago tecnológico, si bien existen razones de índole estrictamente microeconómicas relacionadas con las capacidades de los empresarios del sector, resalta principalmente un Sistema Nacional de Innovación poco desarrollado, con débiles relaciones entre empresas e instituciones del entorno. A su vez, el escaso desarrollo de ciertos mercados críticos (diseño, madera y acabados, partes y piezas) limita en forma considerable el desarrollo de la industria. La existencia de fallas de coordinación relevantes y el escaso desarrollo institucional (tanto formal como informal) actúan también como factores limitantes.

La organización industrial del sector evidencia diferencias considerables con respecto a otros países (como Italia) que también tienen estructuras productivas basadas en PYMES. Se observa un elevado (y en ciertos casos creciente) nivel de integración vertical y una 
reducida difusión de prácticas de subcontratación e iniciativas de carácter asociativo, lo cual afecta la especialización vertical y horizontal del sector. En este sentido, la falta de coordinación impide explotar las ganancias que surgen de la mayor especialización productiva o las economías de escala que presentan ciertas actividades, como la comercialización (principalmente externa) y el diseño.

De este modo, se observa una industria atrasada tecnológicamente, poco especializada vertical y horizontalmente, con bajos índices de competitividad e inserción externa, limitada principalmente a empresas grandes. Ello, en un sector compuesto por micro y pequeñas empresas y con un reducido mercado interno, ha dado lugar a un círculo vicioso en el cual la escasa competitividad limita el acceso a los mercados internacionales y, a su vez, impide alcanzar escalas eficientes de producción y frena el desarrollo de la capacidad innovativa de las firmas locales.

\section{Recomendaciones de politica}

Las políticas públicas que adquieren relevancia para el desempeño y el desarrollo del sector de muebles de madera y su encadenamiento productivo no deben limitarse a las políticas económicas generales que determinan los niveles de estabilidad macroeconómica, competitividad externa e inversión, sino abarcar también las medidas sectoriales que apuntan a atacar los problemas específicos de cada sector. En este contexto, las dirigidas al sector deberían orientarse, principalmente, a fortalecer el Sistema Nacional de Innovación, estimular el desarrollo de experiencias asociativas, en especial en lo referente a la inserción exportadora, atacar las fallas de coordinación y crear instrumentos para disminuir los costos de transacción en ciertos mercados críticos, como el de diseño, madera, acabados o subcontratación.

Se debe tener en cuenta que una reformulación de las políticas productivas debe analizar la estructura institucional del sector público, pues ésta supone:

- Una reorganización de las funciones de los organismos públicos nacionales involucrados en la política industrial.

- Un fortalecimiento institucional de las áreas encargadas de la aplicación de cada tipo de instrumento (incluyendo las áreas de promoción comercial de la Cancillería). Teniendo en cuenta la actual superposición y dispersión de los recursos públicos destinados a los distintos tipos de políticas, creemos que el fortalecimiento institucional no necesariamente implicaría una mayor carga presupuestaria.

- Una adecuada articulación interinstitucional de los organismos públicos nacionales, y entre éstos y los públicos provinciales y federales (CFI).

- Establecer vías de llegada efectivas de los instrumentos a las distintas zonas del país mediante ventanillas únicas en el nivel regional, ya sea por medio de agencias de desarrollo, acuerdos con secretarías de producción municipales u otros mecanismos alternativos.

\section{Désaarrollo}


- Establecer mecanismos institucionalizados de interacción entre los sectores público y privado que propicien la participación activa de este último en la difusión y ejecución de los programas de capacitación y asistencia técnica. También es importante establecer mecanismos de articulación institucional entre las representaciones gremiales correspondientes a los distintos sectores componentes del encadenamiento productivo madera-muebles. En este sentido, el Foro de Competitividad del Mueble y la Madera, iniciativa promovida actualmente por la Secretaría de Industria, constituye un avance que debe profundizarse y sistematizarse. ${ }^{22}$

En lo referente a la promoción de exportaciones, resulta fundamental apuntalar los esfuerzos de inserción internacional de las empresas y los consorcios de exportación, como forma de responder a las fallas de coordinación en esos aspectos (y, de esta manera, sustentar las posibilidad de alcanzar mayores niveles de especialización y escala). En este sentido, resulta necesario un fuerte apoyo en gestión, inteligencia comercial, asistencia técnica y capacitación. ${ }^{23}$

Asimismo, en cuanto a la política comercial, se debería establecer un escalonamiento más pronunciado (en la combinación de reintegros y derechos de exportación) en la relación entre los distintos eslabones del encadenamiento (con el fin de promover las actividades más generadoras de valor), así como una mayor certeza y facilidad en el cobro de los reintegros (o su eventual compensación con los derechos). A su vez, resulta fundamental crear un marco normativo especial para las trading companies, por tratarse de un sector relativamente desconcentrado, con escasa experiencia y cultura exportadora, donde existen altos costos de transacción.

En lo que respecta a las políticas específicas dirigidas al sector, la política forestal debería incorporar:

- Incentivos claramente diferenciados y económicamente significativos que promuevan la forestación de especies usadas por el sector de muebles.

- Acciones tendientes a promover un desarrollo del mercado de la madera que incluya la clasificación de la misma, para abaratar los costos de transacción y obtener de niveles de calidad exigidos a nivel internacional.

22 Este Foro nació a raíz de la intención de promover este tipo de instituciones en el MERcosur. Pero su misión debe ir mucho más allá de las posibles negociaciones o articulaciones con Brasil y, en este sentido, el sector público constituye una pieza clave en el desarrollo de la política industrial sectorial. Nuestro estudio de campo ha permitido constatar que el nivel de conocimiento acerca de la existencia de este foro en el sector privado es todavía muy bajo.

23 En muchos casos se ha observado cierta debilidad en la gestión de los consorcios de exportación, lo cual limita seriamente sus posibilidades de éxito (ausencia de criterios adecuados de selección de em presas participantes, débil seguimiento y control de las actividades de los coordinadores y, fundamen talmente, escaso apoyo por parte de las áreas encargadas de la promoción comercial y asistencia técnica).

\section{DeSarrollo}


En cuanto al desarrollo tecnológico y de recursos estratégicos para el sector, serán fundamentales las acciones dirigidas a fortalecer el Sistema Nacional de Innovación. Resulta imperioso atacar el problema de desconexión entre los centros de conocimiento y la industria mediante directivas más claras en materia de temáticas financiables para la investigación aplicada.

A su vez, es necesario profundizar las acciones de promoción del diseño y su articulación con la industria; para ello es conveniente establecer acuerdos de cooperación con el Centro Metropolitano de Diseño con el fin de involucrar activamente a las empresas de los principales polos muebleros del país. Dicha promoción del diseño podría estar vinculada con la definición de un perfil de especialización sectorial en el que se concentren los esfuerzos públicos. ${ }^{24}$

Adicionalmente, el desarrollo sostenido del sector depende de que Argentina pueda desarrollar recursos humanos de excelencia, tanto con formación universitaria en ingeniería como en caunto a la formación técnica de los operarios. En materia de subsidios para capacitación, asistencia técnica e innovación tecnológica también se observa un nivel de uso relativamente bajo que contrasta con el alcanzado por los programas brasileños. ${ }^{25}$

Dada la importancia que reviste alcanzar mayores niveles de especialización, en lo que se refiere a las prácticas de subcontratación y desarrollo de proveedores debería establecerse, conjuntamente con el sector privado, un programa que favorezcan el desarrollo del mercado de la subcontratación (que asista, además, en la formación de los subcontratistas y participe en mecanismos de evaluación y categorización de los mismos).

Por último, en el marco del MERCOSUR, sería altamente conveniente favorecer el desarrollo de estrategias empresariales que trasciendan la faz comercial y apuntalar los procesos de especialización o complementación productiva.

24 En función de los resultados de nuestro estudio, se aprecia que el perfil de especialización más adecuado para las exportaciones argentinas sería la fabricación de muebles de gama media y media alta, principalmente de madera maciza, con un creciente contenido de diseño local y con mayores aspectos de diferenciación, basados en la utilización de trabajo calificado.

25 Sólo $24 \%$ de las empresas declara haber utilizado el régimen de crédito fiscal, 12\% usó el Programa de Apoyo a la Reestructuración Empresarial para las Exportaciones (PREx) o el Programa de Apoyo a la Reestructuración Empresarial (PRE), y 20\% algún otro tipo de subsidio (FONTAR, PROAMPRO, ProCórdoba, entre otros). Evidentemente, se requiere un fortalecimiento en la gestión de los mismos.

\section{DeSarrollo}




\section{Anexo metodológico}

Los análisis y conclusiones de este trabajo se basaron, en gran medida, en un estudio de campo, llevado a cabo entre mayo y agosto de 2003, como parte del cual se realizaron 42 entrevistas: 25 a fabricantes de muebles y 17 a clientes, proveedores e informantes claves y especialistas sectoriales. Los resultados preliminares del trabajo se presentaron en dos encuentros en los cuales participaron empresarios y miembros de instituciones, públicas y privadas, afines al sector.

La muestra seleccionada de empresas no tuvo ánimo de representatividad estadística, sino que se dirigió principalmente hacia aquellas que, a priori, en función de la literatura existente, aparecieran como las más dinámicas del encadenamiento. De este modo, la muestra se orientó hacia las que mostraran mayor inserción y dinámica exportadora, hubiesen participado en experiencias asociativas o estuvieran localizadas en los principales polos muebleros de Cañada de Gómez y Esperanza. La muestra incluyó a 10 de las 15 primeras empresas exportadoras de muebles de madera, al menos una empresa participante en las experiencias asociativas existentes en la industria de muebles argentina y seis de cada uno de los principales polos muebleros.

Se realizaron entrevistas estructuradas, de aproximadamente dos horas de duración, con una combinación de preguntas cerradas y abiertas. De allí se extrajeron una serie de variables en forma directa, con la intención de recolectar información acerca de:

1. Desempeño de la firma: facturación y su variación, valor de las exportaciones, variación de las exportaciones, porcentaje de éstas en producción total, empleados y variación de empleados, grado de utilización de la capacidad instalada, variación de la rentabilidad;

2. Especialización productiva: mix de producción en cantidad de productos, porcentaje de producción subcontratada y realizada a pedido de terceros, principales causas de la tercerización de la producción;

3. Recursos humanos: profesionalización del personal;

4. Tecnología: disponibilidad de área de diseño o personal profesional dedicado a ello, cantidad de personal, origen, tipo de tecnología de proceso (control numérico, semiautomática, manual), certificaciones de calidad, inversiones en tecnología;

5. Interacciones con proveedores, clientes, empresas competidoras e instituciones del entorno, en los niveles local y nacional: tipo de relación (formal, informal), existencia de intercambio de información técnica, frecuencia de los intercambios de información, principales problemas en la relación con proveedores y clientes, principales problemas para la provisión de insumos, participación en experiencias asociativas, vinculaciones con instituciones del entorno (tipo de relación y frecuencia);

6. Uso de políticas públicas: instrumentos utilizados en lo últimos cinco años; cantidad de veces en que fueron usados; recursos recibidos; fuente de información acerca de la existencia de las políticas.

\section{DeSarrollo}


7. Impacto de la apertura de los noventa, el MERCOSUR y la devaluación de 2002 en la competencia en productos, la apertura del mix de producción y el nivel de especialización, y tecnología de producción.

Enseguida, se construyó una serie de variables a partir de la combinación de distintas preguntas, lo cual sirvió de base para los análisis posteriores. Finalmente, se verificaron los principales resultados obtenidos mediante entrevistas realizadas a diez informantes clave, y dos encuentros con empresarios y miembros de instituciones afines al sector.

Características de la muestra

\begin{tabular}{|c|c|c|}
\hline & Variable & Cantidad de empresas \\
\hline Cantidad de empresas de la muestra & & 25 \\
\hline Tamaño de empresas & Grandes (más de 40 empleados) & 11 \\
\hline Empresas Exportadoras & & 15 \\
\hline \multirow[t]{2}{*}{ Gama } & Baja & 11 \\
\hline & Alta o media alta & 14 \\
\hline Empresas ubicadas en clusters & & 9 \\
\hline
\end{tabular}

Bibliografía

Albaladejo, M., "The Determinants of Competitiveness in SME Clusters: Evidence and Policies for Latin America", en Small-Scale Enterprises in Developing and Transitional Economies, Londres, Macmillan, 2001, pp. 229-255.

Andersen E.S.; B. Dalum, B. Johnson y B.A. Lundvall, "National Systems of Production, Innovation and Competence Building", en Research Policy, vol. 31, núm. 2, febrero de 2002, pp. 312-231.

Bekerman, M. y G. Cataife, "Globalización y encadenamientos productivos. Impacto sobre los países periféricos", en Anales de la Asociación Argentina de Economía Política, Buenos Aires, 2001.

Boscherini, F. y G. Yoguel, "El desarrollo de las capacidades innovativas de las firmas y el rol del sistema territorial", en Desarrollo Económico, vol. 41, núm. 161, Buenos Aires, IDES, abriljunio 2001, pp. 37-69.

Denk, A., Pólos Moveleiros, São Bento do Sul, San Pablo, ABImovel (Associação Brasileira das Indústrias do Mobiliário), 2002.

Dosi, G.; C. Freeman, R.R. Nelson, G. Silverberg y L. Soete (editores), Technical Change and Economic Theory, Londres y Nueva York, Pinter Publishers, 1988.
Dosi, G., K. Pavitt y L. Soete, The Economics o Technical Change and International Trade. Harvest Wheatsheaf, Nueva York y Londres, 1990. FAIMA, Sector Muebles, Buenos Aires, FederaciónArgentina de la Industria Maderera y Afines, 2000.

Fanelli, J.M. y R. Frenkel, "Estabilidad y estructura: interacciones en el crecimiento económico", Documento CEDES núm. 104, serie Economía, Buenos Aires, CEDEs, 1994.

Ferraz Dias de Moraes, M.A. y A.M. Nassar,. Estudo Da Competitividade De Cadeias Integradas No Brasil: Impactos Das Zonas De Livre Comércio, San Pablo, Universidade Estadual de Campinas, Instituto de Economia, Núcleo de Economia Industrial e da Tecnologia (UNICAMP-IE-NEIT), 2002.

Freeman, C., "Continental, National and Sub-national Innovation Systems Complementarity and Economic Growth", en Research Policy, vol. 31, núm. 2, febrero, 2002, pp. 191-211.

Gereffi, Gary y Miguel Korzeniewicz (editores), Commodity Chains and Global Capitalism, Westport, Praeger, 1994.

Gereffi, G.; J. Humphrey y T. Sturgeon, “The Governance of Global Value Chains: An Analytic Framework", mimeo, 2003. 
Giuliani E., "Cluster Absorptive Capability: An Evolutionary Approach for Industrial Clusters in Developing Countries", presentado en la DRUID Summer Conference, Copenhagen/Elsinore, 68 de junio de 2002.

Giuliani, E., "How Clusters Learn: Evidence from a Chilean Wine Cluster" (preliminary draft) EADI Workshop, Clusters and Global Value Chains in the North and the Third World Università del Piemonte Orientale, 2003.

Giuliani, E.; C. Pietrobelli y R. Rabellotti, Upgrading in Global Value Chains: Lessons from Latin American Clusters. Agorà 2000, mimeo para el BID, 2003.

Gorini, A.P.F., A indústria de móveis no Brasil. São Paulo, San Pablo, Associação Brasileira das Indústrias do Mobiliário (ABIMOVEL), 2000.

Hirschman, A.O., La estrategia del desarrollo económico, México, Fondo de Cultura Económica, 1958.

Hoff, K., "Beyond Rosenstein-Rodan: The Modern Theory of Coordination Problems in Development", en Annual World Bank Conference on Development Economics, Washington, World Bank, 2000, pp. 145-176.

Hoff, K. y J.E. Stiglitz, "Modern Economic Theory and Development", en G. Meier y J. Stiglitz (editores), Frontiers of Development Economics: The Future in Perspective, Oxford University Press y Banco Mundial, 2001.

Humphrey J. y H. Schmitz, "Developing Country Firms in the World Economy: Governance and Upgrading in Global Value Chains", en INEF Report, núm. 61, Duisburg University of Duisburg, 2002.

IDS (Institute of Development Studies), Background Notes for Workshop on the Spreading of the Gains from Globalisation, Brighton, Institute of Development Studies, Universidad de Sussex, 1999.

INDEC (Instituto Nacional de Estadísticas y Censos): Censo Nacional Económico 1994. Industria Manufacturera. Total del País, Buenos Aires, Ministerio de Economía, Secretaría de Programación Económica, INDEC, 1994.

_ - Base de Datos de Comercio Exterior. -, Encuesta Industrial Anual.

International Trade Centre UNCTAD/wTO, United States Statistical Division, Base de Datos PC-TAS, 1992- 1996.

International Trade Centre UNCTAD/wTO, United States Statistical Division, Base de Datos PC-TAS, 1995- 1999.

Kaplinsky, R., "Spreading the Gains from Globalisation: What Can Be Learned From Value Chain Analysis", en IDS Working Paper núm. 110, Brighton, Institute of Development Studies, Universidad de Sussex, 2000.

Kaplinsky, R., y J. Readman. "Globalization and Upgrading: What can (and cannot) be Learnt from International Trade Statistics in the Wood Furniture Sector?", Brighton, Institute of Development Studies, Universidad de Sussex, 2000.

Kaplinsky, R.; M. Morris y J. Readman, "The Globalization of Product Markets and Immiserising Growth: Lessons from the South African furniture industry", Brighton, IDS, Universidad de Sussex.

Katz, J., "Cambios en la estructura y comportamiento del aparato productivo latinamericano en los años 1990: Después del Consenso de Washington, Qué?", en Seminario Políticas para Fortalecer el Sistema Nacional de Innovación, Secretaría de Ciencia y Tecnología, Buenos Aires, 1999.

Krugman, P., "Toward a Counter-Counterrevolution in Development Theory", en Proccedings of the World Bank AnnualConferenceonDevelopmentEconomics, Washington, World Bank, 1992, pp. 15-38.

López, A., "Las ideas evolucionistas en economía: una visión de conjunto", en Revista Buenos Aires Pensamiento Económico, núm. 1, Buenos Aires, otoño, 1996

Murphy, K.; A. Shleifery R. Vishny, "Industrialization and the big push", en Journal of Political Economy, vol. 97, núm. 5, 1989, pp. 1003-26.

Nelson, R. y B. Sampat, "Making Sense of Institutions as a Factor Shaping Economic Performance", en Journal of Economic Behavior and Organization, núm. 44, vol. 1, enero de 2001.

Nelson R. y N. Rosenberg, "Technical Innovation and National Systems", en R. Nelson (editor) National Innovation System-A Comparative Analysis, Nueva York, Oxford University Press, 1993.

Nelson R. y S. Winter, An Evolutionary Theory of Economic Change, Cambridge, Harvard University Press, 1982.

North, D., Instituciones, cambio institucional y desempeño económico, México, Fondo de Cultura Económica, 1993.

Nurkse, R., "Algunos aspectos internacionales del desarrollo económico", en The American Economic Review, mayo de 1953, pp. 571-583, reproducido en Okun, B. y W. Richardson, Bilbao, Ediciones Deusto, 1961.

___ , "Further Comments on Proffesor Rosenstein-Rodan's Paper", en Howard S. Ellis (editor), Economic Development for Latin America, Proceedings of a Conference held by the International Economic Association, Nueva York, St. Martin's Press Inc., 1961.

Ocampo, J.A., "Más allá del Consenso de Washington: una visión desde la CEPAL", en Revista de la CEPAL, núm. 66, Santiago de Chile, CEPAL, 1998, pp. 7-28.

Pietrobelli C. y R. Rabellotti (editores), "Upgrading in Clusters and Value Chains in LA. The Role of 
Policies", Report for Agorà 2000 and the Micro and SME Division, Washington, Department of Sustainable Development (SD/MSM) of the InterAmerican Development Bank, 2003.

Pietrobelli, C. y R. Rabellotti, "Competitiveness and upgrading in clusters and value chains. The case of Latin America", presentado en The DTI/UNIDO competitiveness conference. The critical role of institutions at the national and regional level, Pretoria, South Africa, 2004.

Porter, M., La ventaja competitiva de las naciones, Buenos Aires, Ediciones Vergara, 1990.

Rabellotti, R., "Industrial Districts in Mexico-the Case of the Footwear Industry", en Small Enterprise Development, vol. 4, núm. 3, septiembre de 1993.

-, External Economies and Cooperation in Industrial Districts. A Comparison of Italy and Mexico, Londres, Macmillan, 1997.

- "Recovery of a Mexican Cluster: Devaluation Bonanza or Collective Efficiency?", en World Development, núm. 9, vol.27, 1999, pp. 1571-1585.

Rodrik, D., "Getting Interventions Right: How South Korea and Taiwan Grew Rich", en Economic Policy, 1996, pp. 53-107.

Ros, J., La teoría del desarrollo y la economía del crecimiento, México, Fondo de Cultura Económica, 2000 .
Rosenstein-Rodan, P., "Problems of Industrialization of Eastern and Southeastern Europe", en Economic Journal núm. 53, 1943, pp. 202-211.

, "Notes on the theory of the big push", Cambridge, Massachusetts, MIT: Center for International Studies, 1957, reimpreso en Howard S. Ellis (editor), Economic Development for Latin America, Proceedings of a Conference held by the International Economic Association, Nueva York, St. Martin's Press Inc., 1961.

Schmitz, H., "Collective Efficiency: Growth Path for Small-scale Industry", en Journal of Development Studies, vol. 31, núm. 4, 1995, pp. 529-566.

Stiglitz, J., "Economics of Information and the Theory of Economic Development", en Revista de Econometría, núm. 1, 1985, pp. 5-32.

Williamson, O., Las instituciones económicas del capitalismo, México, Fondo de Cultura Económica, 1985

Williamson, O., "The New Institutional Economics: Taking Stock, Looking Ahead", en Journal of Economic Literature, vol. 38, septiembre de 2000, pp. 595-613.

\section{DeSarrollo}

